\title{
La família de Pascual Duarte e La colmena, de Camilo José Cela, por Gonzalo Torrente Ballester e Gonzalo Sobejano: percepções e pontos de vista
}

\author{
La família de Pascual Duarte and La colmena, Camilo José Cela, \\ by Gonzalo Torrente Ballester and Gonzalo Sobejano: perceptions and views
}

Regina Kohlrausch

Pontifícia Universidade Católica do Rio Grande do Sul - Porto Alegre - Rio Grande do Sul - Brasil

\begin{abstract}
Resumo: Este artigo tem por objetivo apresentar a análise de textos de Gonzalo Torrente Ballester e de Gonzalo Sobejano publicados em suas obras Panorama de la Literatura Española Contemporánea (1956) e Novela Española de Nuestro Tiempo (1970), respectivamente, sobre da obra literária de Camilo José Cela. Com base na literatura comparada, visa mostrar percepções e/ou pontos de vista semelhantes e divergentes acerca, especificamente, dos romances La família de Pascual Duarte e La colmena no âmbito da literatura espanhola do período pós-guerra civil espanhola.
\end{abstract}

Palavras-chave: Literatura espanhola; Camilo José Cela; La família de Pascual Duarte; La colmena; Literatura comparada

\begin{abstract}
This article aims to provide na analysis of Gonzalo Torrente Ballester's and Gonzalo Sobejano's texts published in his works Panorama de la literatura española contemporânea (1956) and Novela española de nuestro tiempo (1970), respectively, on the literary work of Camilo José Cela. Based on comparative literature the article aims to show the perceptions and/or the similar and divergent standpoints about specifically the novels La familia de Pascual Duarte and La colmena from the perspective of the Spanish literature in the civil post war period.
\end{abstract}

Keywords: Spanish literature; Camilo José Cela; La família de Pascual Duarte; La colmena; Comparative literatur

Camilo José Cela (1916-2002), nascido em Iria Flavia, na Galícia, Prêmio Nobel de Literatura em 1989, é referenciado na historiografia literária espanhola pelo conjunto de sua produção literária, com destaque para os romances La família de Pascual Duarte (1942) e La colmena (1951), publicados num intervalo de nove anos um do outro. O primeiro marca a estreia de Cela como romancista e o segundo serve para consolidar essa trajetória, já antecedido por outros dois romances, três livros de poesia e um livro de viagem. Este artigo, considerando a singularidade do Autor e respectiva obra no âmbito de literatura em língua espanhola, analisa textos de Gonzalo Torrente Ballester e de Gonzalo Sobejano ${ }^{1}$ nas obras Panorama de la Literatura Española Contemporánea (1956) e Novela Española de Nuestro Tiempo $(1970)^{2}$, respectivamente, sobre a produção literária de Camilo José Cela, visando mostrar percepções e/ou pontos de vista semelhantes e/ou divergentes acerca, especificamente, de La família de Pascual Duarte e de La colmena no âmbito do sistema literário espanhol do período pós-guerra civil espanhola.

\footnotetext{
1 O critério para a escolha dos autores e respectivas obras deve-se ao interesse em verificar o olhar de um romancista, que nesse mesmo período estava escrevendo e publicando textos literários, sobre a produção literária de sua época, e o olhar de um filólogo e crítico literário sobre as mesmas obras, catorze anos depois.

2 Esse livro foi publicado em 1970 pela editora Prensa Española, de Madrid. Cinco anos depois, em 1975, veio à luz a segunda edição 'corregida y ampliada'. Em 2005 foi reeditada a mesma versão de 1975, como primeira edição da coleção Marenostrum, porque, conforme explica Sobejano (2005, p. 13), "indiqué la dificultad, para mí, de actualizar NENT (Novela española de nuestro tiempo) y dije que solo podría imaginar reimprimirlo "tal cual", a Santos Sanz Villanueva se le ocurrió esa solución: volver a ofrecerlo en la misma forma en que apareció la segunda y última vez". Neste artigo, todas as referências são da edição de 2005.
} 
O propósito comparativo apoia-se na concepção de literatura comparada, no sentido interdisciplinar de "poner en relación", como explica Carvalhal's:

El estudio de la literatura más allá de las fronteras de un país en particular, y el estudio de las relaciones entre la literatura, por un lado, y otras áreas del conocimiento o creencias, como las artes (pintura, escultura, arquitectura, música) la filosofia, la historia, las ciencias sociales (política, economía, sociología), las otras ciencias, las religiones etc, por otro. En suma, se trata de la comparación de una literatura con otra u otras, y de la comparación de la literatura con otras esferas de la expresión humana (CARVALHAL, 1996, p. 102).

Ou seja, aproveitar-se do método comparativo para 'colocar em relação' os textos críticos, que se voltaram para a obra de Camilo José Cela, acima referenciados, seguindo, como critério, a ordem cronológica de publicação das obras em estudo. Tal propósito serve, por um lado, para revisitar as interpretações realizadas sobre a essas duas obras fundamentais no contexto da literatura espanhola pós-guerra, e, por outro, contribuir com a divulgação da produção literária de Cela, com vistas à realização de novas leituras e, consequentemente, pesquisas sobre esse destacado autor e sua criação artística ou ainda sobre o papel da crítica e historiografia literárias.

Gonzalo Torrente Ballester comenta a carreira literária de Cela no livro Panorama de la literatura española contemporânea, publicado em 1956, no capítulo intitulado "Las promociones de la postguerra", dividido em doze subcapítulos não numerados - La novela; Camilo José Cela; Carmen Laforet; Algunos premios "Nadal"; Nómina incompleta de novelistas; Las promociones femininas; Los juniores; El teatro; Buero Vallejo; Alfonso Sastre; La poesía lírica; Doce apuestas representativas (José Luis Cano, García Nieto, Alfonso de la Torre, Aurelio Valls, José Luis Hidalgo, Vicente Gaos, Rafael Moraes, Blas de Otero, José Hierro, Carlos Bousoño, Eugenio de Nora y José María Valverde)-, distribuídos num total de 54 páginas compostas de textos e fotos de alguns dos autores mencionados no seu estudo. Destaca-se que esse capítulo encerra a primeira parte do estudo e antecede a segunda parte intitulada "Antologia", onde reproduz fragmentos das principais obras dos escritores selecionados e incluídos nesse "panorama". A terceira e última parte, denominada "Documentos", organiza-se em torno de textos subdivididos em duas categorias: 'Carácter nacional' e 'Vida intelectual'.

Anterior a essa obra, Torrente Ballester já tinha publicado Literatura española contemporánea (18981936), em 1949, em cujo epílogo reconhece a importância de Cela ao perguntar-se sobre qual seria a situação da literatura espanhola se não tivesse ocorrido a guerra civil. Sem alternativa, porque a guerra civil ocorreu, Ballester
(1949, p. 446-447) apresenta duas consequências resultantes do momento vivenciado: a primeira refere-se à existência de uma divisão "de la juventud española en dos parcelas irreconciliables, 'la nacional' y 'la peregrina', cada una de las cuales, a su manera y por mucho que a la otra le disguste, continúa la Historia de la Literatura Española, con sus estilos y características (...)" e a segunda consequência "es la confusión". Sobre esta, afirma que pouco se sabe sobre a convivência entre "los verdaderos escritores" e "los falsificadores de siempre" entre aqueles que estão "al otro lado", mas "de los de aquí tenemos alguna experiencia”, pois, segundo Ballester,

de esta parte, trajo la guerra civil una verdadera voluntad creadora, acaso mal orientada, o desorientada, pero auténtica. Se tradujo en poesía, y a los nombres citados añádase el de Dionisio Ridruejo; y en pensamiento, nombremos Laín Entralgo; y en reflorecimiento de la novela, con Camilo José Cela a la cabeza (TORRENTE BALLESTER, 1949, p. 447).

Ballester, conforme a citação, situa Camilo José Cela como aquele que garantiu o reflorescimento do romance espanhol no período pós-guerra. Esse reconhecimento é retomado no livro de $1956^{4}$, quando direciona seu olhar para a produção literária a partir da guerra civil, definido por ele como "las promociones de la postguerra". Antes de tratar individualmente os autores selecionados, Ballester contextualiza a produção romanesca considerando o período entre 1940 e 1945 e a partir de 1946. Para ele, entre 1940 e 1945, a situação histórica para a geração posterior à Guerra de 36 "no es particularmente favorable", porque

\begin{abstract}
llega a las letras en un momento de aislamiento nacional contemporáneo, de un recrudecimiento del casticismo. (...) Por lo que sea, la literatura permanece encerrada en fronteras nacionales, nutrida de sí misma. Es un buen momento para la búsqueda de antepasados literarios, para restaurar una tradición perdida o crearla. (...) Sin embargo, ni se busca en la tradición, ni se crea, ni se propone seriamente cultivar un orgulloso adamismo. Y lo que se haga en cualquiera de estos sentidos, es obra individual, no generacional. Porque, en efecto, tras una frecuentación fértil de la novela picaresca, surje Camilo José Cela ${ }^{5}$, pero el ejemplo no suscita secuaces (TORRENTE BALLESTER, 1956, p. 442).
\end{abstract}

\footnotetext{
3 Tomando por base o artigo de Henri Remak - Comparative literature. Its Definition and Function - publicado em STALLKNECHT N. P. \& FRENZ, H. (eds). Comparative literature: Method and Perspective. Carbondale, Southern Illinois University Press, 1971, p. 1-57.

4 Anterior ao Panorama, Torrente Ballester publicou o artigo "La Colmena, cuarta novela de C.J.C" em Cuadernos Hispanoamericanos, n. 22 (jul.ago. 1951), p. 96-102, no qual desenvolve uma análise mais extensa e detalhada sobre La Colmena. Esse mesmo artigo foi reproduzido, com alguns cortes, na obra Época contemporánea: 1939-1980, de Domingo Ynduráin, p. 392-398, número 8 da Historia y crítica de la literatura española dirigida por Francisco Rico.

5 Referência à obra Nuevas andanzas y desventuras de Lazarillo de Tormes (1946).
} 
Ao voltar-se para a temática tratada pela narrativa romanesca antes e depois de 1946, Ballester afirma que "La familia de Pascual Duarte es ahistorica" e que a vida espanhola, "entre 1939 y 1946, no halla expresión novelesca (ni dramática, como se verá6). Pero, desde 1946, es la actualidad la que nutre la novela, ya experimentada, ya interpretada" (1956, p. 443). Ao comentar sobre "lo que busca un novelista en la realidad, indica Cela como exemplo de alguém que retratou a realidade na sua obra e não foi compreendido:

\begin{abstract}
Y cuando alguien, como Camilo José Cela, dedica toda una novela a los humildes y descubre resplandores humanos donde aparentemente solo hay cochambre, se le acusa de que sus personajes son insinceros. Se pretende, en una palabra, que la realidad sea novelesca de por sí (según ese concepto de la novela que se acerca al reportaje, al testimonio y al alegato), sin darse cuenta de que es la capacidad poética del novelista la única que puede realizar la transmutación del material, cualquiera que sea su carácter (...). (TORRENTE BALLESTER, 1956, p. 444).
\end{abstract}

Após refletir sobre a questão entre literatura e realidade, reconhecendo que Cela soube olhar a realidade e inseri-la em sua literatura ${ }^{7}$, passa a tratar especificamente da vida e obra do Autor, começando com informações sobre seu local de nascimento, sua filiação, sua formação universitária interrompida pela guerra, sua passagem "fugaz por el periodismo profesional y por la burocracia", ressaltando que "actualmente Camilo José Cela no es más que escritor, aunque de cuerpo entero. Es además, figura literaria buliciosa, nombre siempre actual en el comentario y el chismorreo". (1956, p.447-448). Para Ballester, de todos os escritores surgidos depois da guerra, Camilo José Cela

es el único que ha compuesto su facha y, un poco también, su biografía, heredero voluntario de una tradición decimonónica próxima a extinguirse. (...) Es el único escritor contemporáneo que conoció en edad relativamente temprana las formas contradictorias de la gloria, del elogio encendido al denuesto (TORRENTE BALLESTER, 1956, p.448).

\footnotetext{
$6 \mathrm{Na}$ sequência do capítulo há uma análise da produção dramática espanhola no período em estudo.

7 Em "La Colmena, cuarta novela de C.J.C" (1951), Ballester afirma: "Camilo José Cela ha descubierto la realidad, y de su enorme riqueza ha seleccionado una parcela: me refiero aquí a 'realidad' y 'parcela' sociales, colectivas; pero ha descubierto también a los hombres, uno a uno, y de la complejidad infinita de cada uno ha seleccionado su partecita". In: YNDURÁIN, Domingo. Época contemporánea: 1939-1980, p. 392, número 8 da Historia y crítica de la literatura española dirigida por Francisco Rico.

8 Considerando a data da Carta-Prólogo que abre o livro, corresponde ao mês de maio de 1956.

9 Na citação foi mantida a estrutura e informação original de Ballester, com a exclusão do título Judíos, morros y cristianos (1956), já citado no gênero viagem, porque fica evidente que foi problema de editoração.
}

Da informação biográfica passa à bibliográfica, citando os livros publicados até o momento ${ }^{8}$, unindo-os de acordo com o gênero:
Dos de versos (Pisando la dudosa luz del día, 1941, y Cancioneiro de la Alcarria, 1948), tres de viajes (Viaje a la Alcarria, 1948; Del Miño al Bidasoa, 1952, y Moros, judios y cristianos, 1956), cuatro narraciones cortas (Esas nubes que pasan, 1945; El bonito crimen del carabinero y otras invenciones, 1947; El gallego y su cuadrilla, 1951, y El molinho de viento, 1956), y seis novelas: La família de Pascual Duarte (1941), Pabellón de reposo (1944), Nuevas andanzas y desventuras de Lazarillo de Tormes (1946), La Colmena (1951), Mrs. Caldwell habla con su hijo (1953), La Catira (1955). Finalmente, parte de sus artículos de periódico están recogidos en Mesa revuelta $(1945)^{9}$ (TORRENTE BALLESTER, 1956, p. 448).

Apresentado o conjunto da produção escrita de Cela até aquele momento, Torrente passa a falar, de forma geral, sobre cada uma das obras mencionadas, especialmente os romances. Começa sua apreciação sobre La família de Pascual Duarte afirmando que
apareció en un momento en que la prosa española amenazaba con descomponerse bajo la doble influencia de una inchazón barroca que venía del período anterior y una asnal seriedade, y en que los actos humanos no podían considerarse novelabes si no trasponían, al menos, el límite mínimo de la fazaña. Pascual Duarte narra, efectivamente, fazañas, las de un mozo extremeño en cuyas manos inocentes la caricia se hace agresión, mordisco el beso y crimen la respuesta, capaz de arremeter, a fuer de macho, contra un mulo de labor (TORRENTE BALLESTER, 1956, p. 448).

Para Ballester (ibidem), a intenção da obra "era visiblemente humorística, y la materia, tan fantástica como la de Peter Pan, aunque pintada - o mejor estilizada - según las normas de un realismo grueso de cartel de feria". Reconhece, porém, a qualidade da prosa e a influência da tradição literária anterior que "en constraste con esas exageraciones, la prosa, graciosa y sencilla, con algo de Baroja, se refería al modelo escueto del Lazarillo de Tormes". Segundo ele (1956, p.449), "Pascual Duarte fue una sorpresa, pero su camino, tan personal, no podía servir de ejemplo, aunque haya originado lo que se llamó después del tremendismo". Salienta, ainda, em relação às obras Pascual Duarte, Pabellón de reposo e Nuevas andanzas y desventuras de Lázaro de Tormes (caracterizado como pastiche picaresco), que cada uma marcou "una dirección distinta, y si algo hay en común entre las tres, es la prosa en que están escritas" (ibidem). 
Ballester, após essas considerações, volta-se para $L a$ Colmena afirmando que ela é "la primera novela grande de Camilo José Cela, la única que puede, con entera propiedad, llamarse novela, ya que las anteriores, por su tamaño y el estilo de su narración, pertenecen más bien al género que los franceses llaman nouvelle" (ibidem), ou seja, ao mesmo tempo que reconhece La colmena como um legítimo romance, posiciona-se em relação aos textos anteriores, evidenciando que eles não têm essa mesma unidade e, portanto, estariam mais próximos da "nouvelle" do que do romance.

Seguindo sua exposição, Ballester diz que em $L a$ Colmena predomina totalmente "la materia observada sobre la imaginada" $10 \mathrm{e}$ em relação às personagens, sobre as quais tece comentários mais críticos, no sentido de se contrapor ao estilo de Cela, diz:

sus personajes son tipos vulgares de la vida madrileña, escogidos en las zonas más bajas de su sociedad, vidas dominadas por el hambre y el sexo en las que a veces la ternura o la exaltación alumbran resplendores intensos y fugaces, pero suficientes. Es La Colmena como un gran friso en que las amontonadas figuras se repitiesen periodicamente en actitudes distintas. No hay entre ellas jerarquía (TORRENTE BALLESTER, 1956, p. 449).

Em função disso, para Ballester, não existe uma "composición arquitectónica, sino un montage, exatamente el mismo usado por John Dos Passos en Manhattan Transfers" 11 . Ampliando seus comentários sobre as personagens ${ }^{12}$, reitera, inicialmente, que "la carrera de Camilo José Cela culmina en La Colmena" para, posteriormente, explicar que

en esta novela la pereza imaginativa obliga al autor a multiplicar los personajes, a perseguirlos fugazmente en sus aparencias, a no profundizar en ellos. Describe actos que pueden ser significativos, que parecen abrirnos una puerta sobre una intimidad, sobre un carácter, pero la puerta permanece cerrada, y el novelista salta inmediatamente a otro personaje cuya atractiva superfície le solicita (TORRENTE BALLESTER, 1956, p.450).

\footnotetext{
10 Diferente de La família de Pascual Duarte, onde predomina "la invención imaginativa", conforme "La Colmena, cuarta novela de C.J.C" (1951), In: YNDURÁIN, Domingo. Época contemporánea: 1939-1980, p. 392, número 8 da Historia y crítica de la literatura española dirigida por Francisco Rico.

${ }^{11}$ Essa comparação é melhor desenvolvida por Torrente Ballester no texto "La Colmena, cuarta novela de C.J.C" publicado em Cuadernos Hispanoamericanos, n. 22 (julio-agosto 1951), p. 96-102.

12 Em "La Colmena, cuarta novela de C.J.C" (1951), Ballester expõe seu ponto de vista sobre as personagens de modo mais específico, exemplificando com Filo e don Roberto, para mostrar a necessidade de ampliar dados sobre essas figuras humanas. In: YNDURÁIN, Domingo. Época contemporánea: 1939-1980, p. 396, número 8 da Historia y crítica de la literatura española dirigida por Francisco Rico.
}

Para exemplificar essa ausência de aprofundamento no desenvolvimento das personagens, Ballester reproduz uma fala de "un homosexual" que diz: "vamos al billar de al lado, a ver posturas". Para ele, o leitor, diante dessa fala sem continuidade, "pierde el asidero por el que podría interarse de una vida intera". Na sequência ele reconhece que "tenemos de cada uno de ellos preciosos datos: cómo hablan, cómo se mueven, cómo se visten o cómo viven", porém, escreve Ballester, "no sabemos cómo son". Incomodado com essa forma de Cela de "não mostrar como são" suas personagens, Ballester afirma que

hay que preguntarse, finalmente, si Cela cree que los hombres sean de alguna manera; hay que preguntarse si le interesan de verdad los hombres, o sólo sus actos aislados, ciertos actos (...). Porque el novelista o puede desentenderse del hombre que acaba de hacer algo terrible, o profundo, y Cela lo abandona alegremente, después de haberse recreado en la pura descripción del acto. Por otra parte, su intención caricaturesca, su desumanización del personaje, llega a excesos que no sabemos si conceptuar de retóricos o de truculentos (...) (TORRENTE BALLESTER, 1956, p. 450).

Se a construção das personagens não atende à concepção e à exigência de Ballester, ele reconhece ${ }^{13}$, no entanto, a presença de "elementos escatológicos" como algo apropriado e, por isso, positivo:

Gracioso también, aunque deliberado e inocente, es su gusto por los elementos escatológicos, de los que usa y abusa en sus últimos libros. Lo que en La Colmena valía por su significación humana, em La Catira, en Molino de viento, es puro instrumento de juego (...). Desde Quevedo, no se ha manejado con tanta gracia ese mundo escatológico; pero lo que en las obras de Quevedo representaba crueldad, frialdad, cinismo, en último término, lo que revela un alma duplicada, amarga y dura, en los libros de Camilo José Cela se queda en la pura comicidad intrascendente. Cela no es duro ni cruel, es simplemente juguetón. Su enorme capacidad de ternura queda bien clara en La Colmena (TORRENTE BALLESTER, 1956, p. 450-451).

\footnotetext{
${ }_{13}$ Em "La Colmena, cuarta novela de C.J.C" (1951), Ballester salienta duas qualidades "estrictamente literarias: el primor de la escritura (...) Con procedimientos distintos, la prosa de C. J. C. pertenece al mismo género que la barojiana (quede bien sentado que son especies distintas), y, como ella, tiene un especial encanto lírico de difícil análisis. La segunda cualidad de las 'estrictamentes literárias' se refiere a los diálogos. Los personajes de Cela dialogan, hasta el punto de que narración y diálogo constituyen la totalidad de sus procedimientos. No es un fin en sí, sino que, como la prosa, sirve a la narración y a la caracterización. Se reduce, pues a lo esencial; es breve en las frases, rápido, concebido con sobriedad económica. Cuando alguien dice "Buenos días", hay una razón literaria para que lo diga". In: YNDURÁIN, Domingo. Época contemporánea: 1939-1980, p. 396-397, número 8 da Historia y crítica de la literatura española dirigida por Francisco Rico.
} 
Explicando que não é possível dizer nada definitivo para um romancista aos quarenta anos de idade, apresenta um balanço, reconhecendo a qualidade expressiva de Cela e sua capacidade de percepção da realidade visível:

Cela es un escritor que está empezando, que ha apontado a varias metas y que, a la hora del balance, se encuentra con un instrumento expresivo de extraordinaria calidad, como no lo ha habido en las letras españolas desde Baroja, cuyo estilo, sin embargo, supera en riqueza, en corrección (cuando Camilo José Cela se permite una libertad, suele acertar), en matización. La retina de Cela, privilegiada, y su capacidad para describir de dos plumazos la realidad visible, son instrumentos de gran precio en manos de un novelista (TORRENTE BALLESTER, 1956, p. 451).

No entanto, antes de concluir sua análise, Ballester retoma o ponto fraco, na concepção dele, no que se refere à técnica narrativa de Cela: "le perjudican sus puntos de vista sobre la técnica novelesca y su idea de la vida y del hombre"14 (ibidem). Para Ballester, a maturidade de Cela, como romancista, acontecerá quando

Cela sea capaz de contarnos, en cuatrocientas páginas, la vida de media docena de personajes, por dentro y por fuera, sin efectismos, sin truculencias - la vida de esas pobres gentes vulgares a las que con tanta simpatía se acerca... a jugar con ellas- entonces habrá alcanzado la madurez de novelista. Mientras tanto (...) C.J.C. debe ser considerado sólo como el mejor escritor actual en lengua española (TORRENTE BALLESTER, 1956, p. 451).

De acordo com o exposto, pode-se afirmar que Ballester, por um lado, com o olhar de romancista e, por outro, como historiador da literatura, situando Cela como o melhor escritor atual em língua espanhola, tece suas críticas ao texto e ao estilo de Cela centradas, principalmente, no desenvolvimento das personagens sem desqualificá-lo, ao contrário, reconhece e enaltece a produção literária do colega. Para ele, conforme descrito no decorrer desta análise, não basta revelar como vivem, como falam, como se movem, como se vestem, é necessário dizer como são, para que o leitor possa "enterarse de una vida entera". Pode-se inferir que

\footnotetext{
${ }^{14}$ Em "La Colmena, cuarta novela de C.J.C" (1951), Ballester, ao ressaltar a qualidade dos diálogos, declara, reiterando sua crítica pela ausência de desenvolvimento sobre como são as personagens: "Lo que no hay son divagaciones, pensamientos profundos en el que el autor expresa sus puntos de vista: la técnica de Cela y propia contextura psicológica lo excluye. Me complazco en destacar la idoneidad de este diálogo novelesco a los fines generales de la obra". In: YNDURÁIN, Domingo. Época contemporánea: 1939-1980, p. 397, número 8 da Historia y crítica de la literatura española dirigida por Francisco Rico.

15 TORRENTE BALLESTER, Gonzalo. Ensayos críticos. Barcelona: Destino, 1982.
}

essa postura em relação à construção das personagens está relacionada com sua posição sobre o fazer literário, pois também ele, nessa época, estava produzindo literatura. Além disso, considerando que em 1965 escreveu "Esbozo de una teoría del personaje", publicado posteriormente ${ }^{15}$, é possível pensar que a concepção que defende - "figuras construídas y unívocas" e "figuras intuídas y multívocas" - já estava em fase de elaboração.

Seguindo a motivação para este artigo, esta parte volta-se para a obra Novela española de nuestro tiempo, de Gonzalo Sobejano, a qual está dividida em 13 partes, sequenciada, a partir da terceira, por tipos de romances, caracterizados como "Novela existencial" composta pelos capítulos III, IV, V, VI e VII, "Novela social" composta pelos capítulos VIII, IX, X, XI e XII, "Novela estructural" composta pelo capítulo XIII, e finalizada pelas "Consideraciones finales" e "Selección bibliográfica". Após a "Introducción: primeros pasos" e "La guerra española, objeto de novelas", capítulos 1 e 2, respectivamente, Sobejano passa a tratar de cada uma das tipologias, tendo como ponto de partida a "Novela existencial", iniciando com Camilo José Cela, denominado "III. Camilo José Cela: la enajenación", onde apresenta sua posição sobre o conjunto das publicações até 1974, começando com La familia de Pascual Duarte. Para Sobejano, (2005, p. 61),

con esta obra, según se notó en seguida (...), entró la novela española por esa vía de nuevo realismo y de rehumanización (...). Contra la tónica habitual en aquellos años, el novelista gallego no venía a ofrecer al lector literatura evasiva, pero tan poco bélica (...). Prefirió ejecutar un trabajo insólito. Y es seguramente este propósito de novedad de Cela lo que explica no sólo la sacudida que produjo su primera novela y el rápido prestigio que le granjeó, sino también el hecho de que cada una de sus novelas posteriores represente un experimento diverso, y acaso también la circunstancia de haber pasado largos años sin publicar novelas como si temiese, ante sí mismo, no lograr algo a la vez distinto y mejor que lo precedente (SOBEJANO, 2005, p.61).

Conforme Sobejano (ibidem), o êxito de Cela devese a seus indiscutíveis dotes de escritor: "ingenio fértil, penetrante observación, humanismo de fondo, sentido para jugar el juego del arte, conocimiento vasto y depurado de los recursos del idioma, perseverancia, impetuosidad, gracia". Segundo ele, tais dotes, reconhecidos por "casi todo el mundo", revelam-se "aunque con cierta tendencia a la autoimitación", nos numerosos livros de viagens, contos, artigos, ensaios e poesias e nas nove obras que Cela define como romances: "La familia de Pascual Duarte, 1942; Pabellón de reposo, 1944; Nuevas andanzas y desventuras de Lazarillo de Tormes, 1944; La 
colmena, 1951; Mrs. Caldwell habla con su hijo, 1953; La Catira, 1955; Tobogán de hambrientos, 1962; San camilo, 1936 (1969), y Oficio de tinieblas, 1973". (2005, p. 61). Sobejano (2005, p.62) afirma ainda que desses nove romances, La família de Pascual Duarte e La colmena, além de serem "aquellas que han abierto rutas nuevas a la literatura narrativa española y servido de ejemplo a novelistas más jóvenes", obtiveram várias reedições e também atenção universal.

Prosseguindo em sua análise, Sobejano (2005, p. 65) explica que La familia de Pascual Duarte, além de oportunizar "el afortunado comienzo ocasional de un renacimiento de la narrativa española", seria adequado ou "justo mirarla como un primer paso hacia un realismo existencial que pronto habría de generar otro modo de realismo social implícito en el primero". Para justificar a vinculação da obra ao realismo existencial, Sobejano destaca "su tema (la perdición de un hombre), sus motivos (violencia, ensimismamiento) y su fondo (campo español, desenlace en la guerra) con otras obras que, a primera vista muy desemejantes, concuerdan en algo o en mucho con su sentido total" (ibidem).

Em relação aos modelos literários perceptíveis em La familia, é fácil reconhecer marcas da picaresca antiga, da tragédia rural e mítica de Valle-Inclán e García Lorca, porém, alerta Sobejano, onde mais se evidencia a aparição de um escritor "de grandes dotes" não é na composição do conjunto nem na adoção dos modelos mencionados acima, mas no "poder de representación concreta atemperada al alma del protagonista, el trémolo quejumbroso que impregna la confesión y un nuevo modo de dar a sentir la crueldad y la piedad" (2005, p. 68). O estudioso salienta ainda que mesmo que La família se aproxime mais de um relato do que de um romance, o autor demonstra possuir a mais "alta facultad del novelista: el don de representar a la conciencia del lector todo un mundo, todo un ambiente fascinador en sus objetos, personas y relaciones" (ibidem).

Sobre o modo de "sentir a crueldade e a bondade", Sobejano explica que o contraponto de crueldade e piedade de Pascual Duarte tem "una función moral de autoconocimiento y purificación. No es mero tremendismo, no es artificiosa ostentación de horrores y ternuras adrede. Expresa el odio contra una realidad injusta y el anhelo de concordia, la necessidad de amor, del hijo desvalido" (2005, p. 70$)$. No que se refere ao "tremendismo", Sobejano contesta a afirmação de que Cela seria "el iniciador de un nuevo movimento al que se llamó tremendismo", lembrando que não se trata de "una nueva corriente literaria", porque desde o romantismo se configura "la propensión a revelar, en obras literarias, aspectos de la realidad horribles por su violencia, por su fealdad o por su abyección, se encuentra a cada paso" (2005, p. 70-71).
Sobejano, buscando justificar essa propensão de Cela em mostrar as misérias físicas e morais do homem, apresenta as seguintes causas: a primeira pode ser encontrada em sua autobiografia, La cucaña, cujos testemunhos permitem "atribuirle una inclinación personal a ciertas experiencias 'raras': malos olores, palabras obscenas, gestos de crueldad seguidos de arrepentimientos"; a segunda pode ser atribuída ao início de sua carreira literária como poeta surrealista, pois "el surrealismo es una concepción del mundo que se distingue sobre todo por el empeño de liberar aquella parte de la total conciencia que yace en la sombra de las represiones", vinculado ao contexto dos anos "anteguerra y pós-guerra, tan agitados y turbios, que tenían que fomentar, en escritor de semejante caráter y tales propensiones, la tendencia a manifestar miserias y violencias vividas", por fim, destaca os escritores preferidos de Cela que realizaram "la transposición artística de lo feo y lo monstruoso: Quevedo, Baroja, Valle-Inclán, Solana" entre outros (ibidem).

Nesse seu estudo, em conformidade com a ordem cronológica das publicações, comenta as demais obras até chegar em La colmena, declarando que "la novela más ambiciosa de Cela, la que ha tenido mayor influjo en los rumbos de la narrativa española de pós-guerra, es sin duda su cuarta novela: L a colmena $^{16}$, publicada en Buenos Aires en 1951". O estudioso, depois de transcrever a declaração de Cela apresentando La colmena ${ }^{17}$, afirma que se trata de um romance sem protagonista e sem assunto e que

los personajes que en ella aparecen, desaparecen y reaparecen fugazmente llegan al número de 296, más los personajes reales aludidos, que son 50. El diálogo hace visibles y audibles a todos esos pobres hombres y mujeres que gozan y sufren, en el Madrid nocturno de 1942. No hay retratos ni etopeyas. Las figuras se definen hablando y moviendose, y su intermitente reaparición, en breves escenas que reflejan, simultáneamente, su vivir, compone una especie de estridente sinfonía en que la masa diafaniza su ajetreada existencia a manera de una colmena en incesante y vano bullir. Protagonista es, por tanto la vida, de la que esas gentes son vehículo (SOBEJANO, 2005, p. 77).

\footnotetext{
${ }^{16} \mathrm{Na}$ "Nota preliminar de la primera edición" de La novela española de nuestro tiempo, Sobejano (2005, p. 05) conta que leu La colmena em 1952 e que ficou tão impressionado que "transcribí en mis cuadernos casi una tercera parte, rodeada de anotaciones que la lectura me sugería. $L a$ colmena significó para mí la revelación del mundo en que nebulosamente había estado viviendo, y revelaciones de arte y vida, muy semejantes, me proporcionaron después El Jarama, Los bravos y, más tarde, Tiempo de silencio, Cinco horas con Mario y Señas de identidad. (Menciono estas obras por el orden en que las fui conociendo)".

17 "En La colmena salto a la tercera persona. La colmena está escrita en lo que los gramáticos llaman presente histórico (...), es una novela reloj, una novela hecha de múltiples ruedas y piececitas que se precisan las unas a las otras para que aquello marche. En La colmena no presto atención sino a tres días de la vida de la ciudad, o de un estrato determinado de la ciudad, que es un poco la suma de todas las vidas que bullen en sus páginas, unas vidas grises, vulgares y cotidianas (...). La colmena es una novela sin héroe, en la que todos sus personajes, como el caracol, viven inmersos en su propia insignificancia". (SOBEJANO, 2005, p. 76-77, originário do prólogo a Mrs. Caldwell, p. 14)
} 
Em relação ao espaço e ao tempo afirma: "El escenario, la ciudad: en sus cafés, tabernas, bares, burdeles, habitaciones, calles y plazas. Y la noche tiende su sombra sobre la angustiada vida de esa ciudad, que no se describe, que se presenta en su inquietud, en la maraña de los caminos inciertos" (ibidem). É nesse espaço e nesse tempo, explica o estudioso, que se vê desfilar personagens diversos, entre eles

al intelectual pobre (Martín Marco, el único que podría aspirar a protagonista), a los pobladores asíduos de un modesto café (el joven poeta, la prostituta, el señor importante, el limpiabotas, los camareros, la dueña del café). Vese al gitanillo mendicante, al viejo libertino, a la joven obrera que se vende a otro para comprar medicinas al novio, a los novios burgueses que esconden su amor en una casa de citas, a los homosexuales, al vulgar opositor a notarías, al matrimonio hastiado, a la alcahueta, al tabernero lector de Nietzsche, a los guardias que piden la documentación ... (SOBEJANO, 2005, p. 77).

complementando que pouco sabemos de sua fisionomia, de sua história, "ni llegamos a su interior si no es tras las señales de su conversación o en entrecortados monólogos. Conocemos casi exclusivamente como se mueven, como hablan, lo que hacen en determinado momento. Por fuera". (ibidem). Para ele, essa técnica, que leva de um ângulo a outro, de um lugar a outro, de um momento a outro, usada em La colmena não é nova e que "el modelo más próximo a Cela debió de ser la obra de Dos Passos, el cual, no hay que orlvidarlo, había pasado del esteticismo a la crítica influido en parte por Pío Baroja, a quien dedica un ensayo en su libro Rosinante to the Road Again (1922). Sobejano (2005, p. 78) salienta, no entanto, que essa técnica, "que suele denominarse 'pluriperspectivista', 'behaviorista o 'conductista' y, de un modo más general, 'objetivista', era hasta Cela desconocida en España" tendo como único precedente Valle-Inclán, que era um dos mestres de Cela. Nesse sentido, para ele, Cela não imita propriamente a nenhum dos modelos ${ }^{18}$, pois

La difícil organización del libro revela un esfuerzo de reconstrucción personal y una estilización de los fragmentos presentativos no compatible con la grabación rigorosamente fiel del hablar de la gente. Además, el caos rotatorio en que aquí se ofrece la vida ha sido concebido como una conmovedora crónica de amor y pobreza (SOBEJANO 2005, p. 78).

No que se refere ao tema central de La colmena, Sobejano afirma ser a incerteza dos destinos humanos: "las gentes no saben adónde van, cuál podría ser su finalidad" e que o subtema mais importante é a falta de comunicação: "todos viven como separados, en celdillas clausuradas, solos", cujas situações típicas "son el vacío, la repetición, la náusea, la desesperación”, que resulta em formas de comportamento violentos, rotineiros e ensimesmados, acompanhadas de obsessões por "el sexo, el dinero, el recuerdo de la guerra" (ibidem). Para ele, Cela, ao abordar essas situações, revela o resultado "más dolorosamente transcendental del desarrollo moderno: la alienación, es decir, el extrañamiento del individuo respecto a los otros y respecto de sí mismo" (ibidem). Ao revelar esse tipo de alienação, ou seja, de uma massa alienada que recusa uma identificação solidária, conforme Sobejano, La colmena representa um documento de sensibilidade existencialista. Além disso, complementa o estudioso, ela, La colmena, num grau mais elevado do que as obras anteriores e posteriores, abre caminho em direção ao realismo social, que posteriormente marcou a literatura espanhola ${ }^{19}$ :

No se trata ya de un individuo aislado (Pascual Duarte, Lazarillo) ni de una pluralidad de individuos relacionados por una circunstancias que en cualquier momento puede afectar al ser humano (los enfermos de Pabellón de reposo): se trata de la sociedade española en una fase determinada de su historia y en una concreta situación (SOBEJANO, 2005, p. 80).

Sobejano afirma, com base em Castellet $^{20}$, que as três virtudes capitais do La colmena "eran el realismo, la modernidad y la vinculación con una tradición española", salientando que nessa tradição deve-se incluir a ValleInclán "con más derecho que a Quevedo o Baroja, y aunque la modernidad se aminore un poco teniendo en cuenta que los procedimientos más seguros de La colmena se hallan en obras publicadas durante los años veinte por Dos Passos y el mismo Valle-Inclán”, mas que a maior virtude consistia em mostrar a problemática do homem espanhol atual: "su incertidumbre, su incomunicación, su desesperación” (2005, p.81). A partir disso, conclui

\footnotetext{
18 Conforme Sobejano (2005, p. 77), essa linha narrativa com perspectivas diversas estava aberta desde "los experimentos de Henry James y de Joyce a través de obras tan revolucionarias como Les faux monnayeurs (1925), de Gide; Manhattan Transfer (1925), de John Dos Passos; Poin Counter Point (1928), de Huxley; Berlin-Alexanderplatz (1929), de Döblin, o Le sursis (1945), de Jean Paul Sartre".

19 Para Sobejano (2005, p. 81), três pontos estruturais da obra La colmena foram utilizados no romance social de 1950 em diante: "la concentración del tiempo, la reducción del espacio, la protagonización colectiva".

${ }^{20}$ Conforme Sobejano (2005, p. 81), José María Castellet, em "Notas sobre la literatura española contemporanea", de 1955, p. 63, "ponderaba las tres circunstancias por las cuales merecía La colmena excepcional atención: ser "la primera, la única novela española que, en los últimos quince años, lleva consigo la problemática del hombre español actual", ser "la única novela española que se expresa en un lenguaje literario cuya técnica y espiritu están al día, dentro de su tiempo" y estar el libro "dentro de la mejor, quizá de la única línea posible de nuestra novela: la que arranca de la picaresca para acabar, inmediatamente antes de $\mathrm{La}$ colmena, en Baroja". O texto de Castellet, um fragmento, foi reproduzido In: YNDURÁIN, Domingo. Época contemporánea: 1939-1980, p.398-401, número 8 da Historia y crítica de la literatura española dirigida por Francisco Rico.
} 
Sobejano, "se multiplicarían los testimonios veraces, unos mejores y otros peores artisticamente, pero todos deudores a la obra de Cela en cuanto a voluntad de revelación y denuncia" (ibidem).

Convém, ainda, retomar a posição de Sobejano sobre a questão relacionada à falta de detalhamento ou sobre a superficialidade acerca das personagens. Segundo ele, essa elemento narrativo foi destacado de forma positiva ou negativa pelos comentadores da obra de Cela e que talvez não se tenha analisado suficientemente para perceber que essa "especie de impasible objetividad para captar sólo el exterior de las gentes no es tanto un propósito técnico cuanto el resultado de la dificultad del autor para comunicarse con ese mundo reflejado" (2005, p. 80). Para ele, está claro que se Cela não "se interna en las almas" dos indivíduos que contempla é porque "se siente ajeno a ellos, distante, incapaz de convivir, ni aun imaginariamente, con ellos, y por tanto de infundirles más vida de aquella que por fuera, muy volatizada, presentan" (ibidem). No entanto, alerta Sobejano (2005, p. 80), "Cela da indicios de simpatía o antipatía hacia sus criaturas más a menudo de lo que a primera vista parece. No siempre es ajeno a ellas: conservando la distancia, a veces las acompaña y desvela un poco su remoto interior".

Levando em conta a análise de Sobejano aqui exposta, nela também se conforma o reconhecimento da importância das obras de Camilo José Cela no sistema literário espanhol. Percebe-se na exposição, evidente em função da proposta do seu livro, um estudo mais detalhado, com a vantagem da distância temporal entre a publicação de um e de outro, possibilitando, por isso, contar com fontes diversas para validar seus pontos de vista sobre cada um dos romances de Cela. Além disso, diferente de Ballester, o olhar de Sobejano incide para uma categorização das obras, situando cada uma delas dentro de uma tipologia, ou seja, La família de Pascual Duarte abre os primeiros passos em direção ao romance existencial e La colmena alinha-se em direção ao realismo social, servindo de modelo para os futuros escritores.

Considerando o olhar analítico de cada um dos estudiosos selecionados para este estudo, colocando-os em relação, conforme propósito comparativo, evidencia-se o predomínio de pontos de vista semelhantes e/ou coincidentes: (a) ambos afirmam que graças a essas duas obras, La família da Pascual Duarte e La colmena, o romance espanhol renasceu, abrindo novos caminhos e servindo de exemplo para os jovens romancistas; (b) ambos destacam a capacidade de Cela de retratar a realidade e mostrar a problemática do homem espanhol atual (anos 40); (c) ambos salientam a vinculação de Cela com a tradição espanhola especialmente relacionada ao elemento picaresco e a situações que remetem a Baroja, a Valle-Inclán, a Quevedo entre outros; (d) ambos ressaltam a presença da mesma técnica narrativa utilizada por John Dos Passos, lembrando que na Espanha, com exceção de Valle-Inclán, mestre de Cela, essa técnica sinaliza para a renovação literária a partir de Cela; (e) ambos reiteram tratar-se de um grande escritor em função da eficiência técnica, da qualidade das narrativas, do depurado conhecimento do idioma, da capacidade de perceber e retratar a realidade espanhola com maestria; (f) ambos declaram que La colmena é o romance que mais influenciou os rumos da narrativa espanhola dos anos 50 em diante.

No que se refere às percepções divergentes, duas são as mais salientes: a primeira diz respeito ao tremendismo, entendido como movimento ou característica literária, e a segunda às personagens. Sobre o tremendismo, enquanto Ballester afirma tratar-se de uma característica original de Cela em La família de Pascual Duarte, Sobejano contesta declarando que não se trata da criação de uma nova corrente literária, porque desde o romantismo se configura essa tendência de mostrar aspectos horríveis da realidade, por sua violência e monstruosidade, em obras literárias, ao relatar misérias e violências vividas e/ou experimentadas. Sobre as personagens, ambos coincidem que pouco se sabe de sua fisionomia, de sua história, de seu interior e que se conhece apenas como se movem, como falam ou o que fazem em determinados momentos. Em função disso, enquanto Ballester aponta para um tipo de "pereza imaginativa" e/ou de problema de domínio de técnica narrativa o fato de não mostrar como são as personagens, Sobejano justifica dizendo que não se trata apenas de um propósito técnico, mas da dificuldade do próprio autor em se comunicar com esse mundo retratado, ou seja, Cela, mesmo dando indícios de simpatia ou antipatia por suas criaturas, não 'entra' em suas almas porque se sente alheio, distante, incapaz de conviver com elas e lhes dar mais vida do que essa vista apenas por fora. Convém salientar que essas posições não desqualificam o trabalho literário de Cela, ao contrário, colocam em diálogo elementos que contribuíram para o renascer da literatura espanhola no contexto histórico da escrita e publicação das duas obras analisadas.

Para concluir, com vistas a futuras pesquisas, as relações aqui estabelecidas, coincidentes e/ou divergentes, entre Gonzalo Torrente Ballester e Gonzalo Sobejano acerca das obras La família de Pascual Duarte e La colmena, de Camilo José Cela, além de confirmar a importância do Autor e o significado de cada uma das obras no âmbito da literatura espanhola, dialogam entre si e com demais estudiosos, validando o sistema literário espanhol, sinalizam para uma reflexão acerca do papel do historiador da literatura e do crítico literário e suas limitações em relação aos seus objetivos: como dar conta de um panorama da literatura, objetivo de Ballester, ou 
apresentar uma exposição orientadora sobre as obras de um determinado período, propósito de Sobejano, e evitar a superficialidade ou o excesso da valorização do corpus em estudo? Fica o convite.

\section{Referências}

CARVALHAL, Tania Franco. Literatura comparada. Buenos Aires: Corregidor, 1996.

CASTELLET, José María. La colmena, Notas sobre literatura española contemporánea. Barcelona: Laye, 1955. p. 63-74. In: YNDURÁIN, Domingo. Época contemporánea: 1939-1980. 2. ed. Barcelona: Editorial Crítica, 2004. p. 398-401.

MOREIRA, Maria Eunice; JACOBY, Sissa (org.). Viagem ao Brasil: o Nobel Camilo José Cela na PUCRS. Porto Alegre: EDIPUCRS, 2009.

NITRINI, Sandra. Literatura comparada: história, teoria e crítica. 2. ed. São Paulo: Editora da Universidade de São Paulo, 2000 .
ROMERO LOPEZ, Dolores (org.). Orientaciones en literatura comparada. Madrid: Arco/Libros, 1998.

SOBEJANO, Gonzalo. Novela española de nuestro tiempo 1940-1974. 3. ed. Madrid: Marenostrum, 2005.

TORRENTE BALLESTER, Gonzalo. Epílogo. In: TORRENTE BALLESTER, Gonzalo. Literatura española contemporánea (1898-1936). Madrid: Afrodisio Aguado, 1949. p. 443-451.

TORRENTE BALLESTER, Gonzalo. La Colmena, cuarta novela de C.J.C. Cuadernos Hispanoamericanos, n. 22, p. 96-102, jul.-ago. 1951. In: YNDURÁIN, Domingo. Época contemporánea: 1939-1980. 2. ed. Barcelona: Editorial Crítica, 2004. p. 392-398.

TORRENTE BALLESTER, Gonzalo. Panorama de la literatura española contemporánea. Madrid: Guadarrama, 1956.

Recebido: 02/12/2015

Aprovado: 20/01/2016

Contato: regina.kohlrausch@pucrs.br 